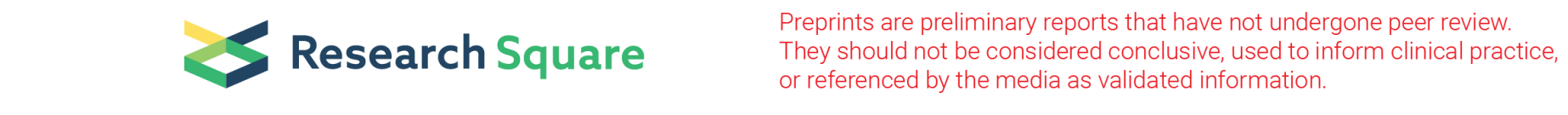

\title{
Title: Efficacy of Psychosocial Group Treatment for Post-traumatic Stress Disorder among Genocide Survivors in Rwanda, 25 Years After 1994 Genocide Against Tutsi.
}

Clarisse Marie Claudine SIMBI

Ningxia Medical University

Yuhong Zhang ( $\sim$ zhabour@163.com )

Ningxia Medical University

Zhizhong Wang

Ningxia Medical University

\section{Research Article}

Keywords: PTSD, Post-traumatic stress disorder, Genocide survivors, 1994 Genocide against Tutsi, Group therapy

Posted Date: July 30th, 2021

DOI: https://doi.org/10.21203/rs.3.rs-730323/v1

License: (c) (i) This work is licensed under a Creative Commons Attribution 4.0 International License. Read Full License 


\section{Abstract}

Background: Prior studies indicated that post-traumatic stress disorder is becoming a global health concern even though still poorly known and treated. In the aftermath of 1994 Genocide against Tutsi, studies found high rates of depressive and anxious symptoms along with PTSD among genocide survivors. Due to the highest cruelty in which the Genocide was committed, genocide survivors still need high special humanitarian services, of those including specialized health care services. The aim of this study was to assess the efficacy of psychosocial group therapies created by AVEGA Agahozo in reducing PTSD symptoms among Genocide survivors in Rwanda, 25 years after 1994 Genocide against Tutsi.

Methods: We conducted a comparative cross-sectional study design with a sample of 98 genocide survivors who received group therapy by AVEGA Agahozo. We used a multi-stage random sampling method to select participants and 7 trained psychologists interviewed genocide survivors about their PTSD status before and after treatment using Diagnostic and Statistical Manual of Mental Disorders, 5th Edition. The analysis was performed using SPSS version 17.1.

Results: The results showed that women were $97.96 \%$ and men presented $2.04 \%$ of all participants because AVEGA Agahozo mainly focuses on helping women survivors who lost their husbands in Genocide and previous findings also concluded that women are very prone to suffer from PTSD than men. Paired t-test results showed significant differences between symptoms, before and after treatment $(P<0.001$ in all pairs). Cohen's $d$ results also showed high effect sizes $(d>0.5)$, only in pair 8 where the difference appears to be less significant $(d=0.28)$. The descriptive statistics showed that the severity of PTSD symptoms dramatically reduced after treatment. But this difference of severity is only statistically significant among five (5) PTSD symptoms.: (Marked physiological reactivity after exposure to trauma-related stimuli $[P=0.045, x 2=38.111]$; inability to recall key features of the traumatic event $[P<001, x 2=56.309]$; persistent negative trauma-related emotions $[P=0.013, x 2=43.184]$; selfdestructive or reckless behavior $[P=0.041, x 2=38.535]$; hypervigilance $[P=0.020, x 2=41.596]$.

Conclusion: Psychosocial group therapies created by AVEGA Agahozo effectively alleviate post-traumatic stress disorder symptoms and severity among genocide survivors.

\section{Background}

Post-traumatic stress disorder (PTSD) is mainly characterized by exposure to a traumatic event in which the "person experienced, witnessed, or was confronted with a terrifying event or events that may cause death, severe injury, physical harm or threat of self or others [1]. Many people who develop PTSD at the first onset will recover without the use of any treatment a few months later, however, in a large subgroup (30-40\%) the symptoms persist, repeatedly for many years [2],[3]. A study conducted with World War II [4] and Holocaust survivors [5] found that the suffering lasts for decades after the traumatic event has ended [6]. In the aftermath of 1994 Genocide against Tutsi, genocide survivors showed high rates of mental health and psychosocial problems due to the inconceivable, dehumanized brutality that the majority of them had been exposed or witness to [7]. In the census conducted by the Ministry of Local Government and the Ministry of Health in 2002, the findings showed that the prevalence of PTSD in genocide survivors was around $87.4 \%$ [8]. A recent study conducted 25 years after the Genocide found that genocide survivors still present a high prevalence of posttraumatic stress disorder notably in women survivors [9]. And most of them are not receiving the appropriate 
treatment to help them recovering from PTSD. AVEGA Agahozo is one of the institutions in Rwanda which is trying to help genocide survivors to recover from PTSD by giving them PTSD group treatments. They have professional psychologists checking on them regularly and give them any psychosocial assistance they need to thrive. They also help them to fix their personal issues including access to other health care services to those who have chronic diseases caused by Genocide. AVEGA Agahozo has created different group therapies in almost all districts of Rwanda. And many genocide survivors have profoundly confirmed that group therapies have helped them to recover from PTSD and regained hopes for living a better life. There were no previous studies that evaluated or analyzed the efficacy of these therapeutic groups in healing PTSD. The present study was designed to analyze the efficacy of these psychosocial group therapies created by AVEGA Agahozo in reducing PTSD symptoms and severity among Genocide survivors.

\section{Methods}

\section{Research design}

We used a comparative cross-sectional study design to analyze the efficacy of psychosocial groupies created by AVEGA Agahozo. According to the DSM-5 criteria for PTSD (Table 1), 20 symptoms before and after treatment were compared to analyze the efficacy of psychosocial group therapy in reducing PTSD symptoms among genocide survivors. The genocide survivors were asked how they felt before joining the psychosocial group therapy and how they felt after treatment, then after the records were compared to assess the change in PTSD symptoms and severity before and after treatment. The severity of symptoms was measured by choosing the intensity of reoccurrence or re-experience of the symptoms. The intensity of PTSD symptoms severity was categorized into 6 levels (Not at all, very slightly, slightly, moderately, quite a bit and extremely) (Table 4).

\section{Description of group therapy in this study}

In this study, group therapies represent the psychosocial therapeutic groups created by AVEGA Agahozo to help genocide survivors to recover from PTSD. AVEGA Agahozo has several numbers of psychologists working in daily basis with genocide survivors. They are the staff of AVEGA Agahozo which is an association of the widows of Genocide. It is a Rwandan association formed to help widows, orphans and others who lost family members in the 1994 Genocide. AVEGA Agahozo was founded in October 1995 by women who had survived the killings but lost their husbands. As one of the mission of this association, AVEGA Agahozo generally helps genocide survivors who are suffering from different chronic health conditions. And that is where started the idea of creating group therapies to help widow genocide survivors to recover from PTSD. These group therapists teach genocide survivors new coping skills on how to manage their symptoms, reduce painful memories, overcome their sense of helplessness and hopelessness, develop healthy lifestyle habits, manage anxiety and anger, think positively, give a hand to others, and move on with their lives. The therapists ensure that every group therapy is secured with emotional safety, confidentiality, support, and a common goal (of recovering from PTSD), to help group members having a sense of belonging, acceptance and feel free to share their testimonies, strengths, and weaknesses throughout the healing journey. This makes genocide survivors feel less isolated knowing how to deal with the trauma. Each group therapy had 9 to 18 participants. All group therapies lasted for a period of 6 to 30 months depending on how long the members showed a tremendous recovery from PTSD. All group therapies included in this study were created and closed within the years from 2016 to 2019. The range of age mean of group members was 43-64 years. The group therapy sessions lasted usually for one to two hours, and they were 
repeatedly happening once to twice a week depending on how the group members needed the support to help them recover from PTSD.

\section{Participants}

Participants were 98 genocide survivors who were suffering from PTSD and who received psychosocial group treatment by AVEGA Agahozo. The age range of participants was 43 to 64 years. These group therapies were located in ten (10) districts of Rwanda (Bugesera, Gisagara, Huye, Gakenke, Rulindo, Musanze, Nyamasheke, Karongi, Kayonza, and Ngoma).

Inclusion criteria: (1) Participants were genocide survivors; (2) Participants were born prior to genocide, (3) Participants suffer from PTSD; (4) Participants were able to recall what happened to them during the Genocide (5) Participants experienced at least one traumatic event during the Genocide; (6) Participants had received PTSD group treatment under the supervision of AVEGA Agahozo within the years from 2016 to 2019, and (7) Participants were no longer receiving psychosocial group therapy.

Exclusion criteria: (1) Those people who are not genocide survivors; (2) who were born after Genocide, (3) who do not suffer from PTSD; (4) who did not experience traumatic events during the Genocide; and (5) who did not receive PTSD group treatment under the supervision of AVEGA Agahozo within the years from 2016 to 2019.

\section{Subjects sampling and selection}

We used a multi-stage random sampling method to select 98 participants. We firstly selected 10 districts (Bugesera, Gisagara, Huye, Gakenke, Rulindo, Musanze, Nyamasheke, Karongi, Kayonza and Ngoma) randomly among 14 districts which had graduated group therapies created and supervised by AVEGA Agahozo. In each selected district, one sector was selected, thereafter; in each selected sector one group therapy was selected. In each selected group therapy, ten genocide survivors precisely were randomly selected to participate in the study but if the members of group therapies were less than 10, all of the members were selected to participate in the study. All genocide survivors who met the inclusion criteria were given equal chance to participate in the study. Microsoft Excel was used to sort randomly the names of participants to participate in the study using a sampling frame containing all the names of genocide survivors in each psychotherapy group.

\section{Data collection}

Seven psychologists collected data in October, 2019 from 10 selected districts of Rwanda (Bugesera, Gisagara, Huye, Gakenke, Rulindo, Musanze, Nyamasheke, Karongi, Kayonza and Ngoma). One week before collecting data, we recruited 7 psychologists and trained them to have the same understanding of the study methodology and objectives. Twenty psychologists submitted their copies of degrees and CV, then after we reviewed their documents and chose those who were more closely to fit the requirements. Selected psychologists had experience of two years and more in conducting trauma focused therapies. The training was conducted online because the psychologists were located in different areas of the country. All data collection sites were nearby health centers that in case the interviewees re-experienced the occurrence of the traumatic events, they would have received emergency care services from the health centers. Each site was supervised by the psychologist who led the group therapy since when it was created. And the research team coordinated all the research work. The interviews included open ended and close questions. The psychologists explained clearly the objectives of 
the study to the participants before they started interviews, then after they carefully interviewed 98 genocide survivors who met the inclusion criteria using a questionnaire which was designed in reference of the Diagnostic and Statistical Manual of Mental Disorders, $5^{\text {th }}$ Edition. The interview lasted between 30-60 minutes. The participants had to sign a consent form before they participated in the study and they were allowed to stop or withdraw from the interview whenever they felt uncomfortable. We collected the information on demographic characteristics of participants, description of group therapy, symptoms identified before treatment and symptoms identified after treatment. To increase the quality control of the study, we involved the psychologists to conduct the interview and did piloting as to test and adjust the questionnaire before it was fully certified for use. The psychologists were mostly trusted by the participants and they knew how to handle any situation that might cause trauma reoccurrence during the interviews. This was not only demonstrated that the target population understood the questions in the same way as the researchers but also offered an opportunity to identify errors in the questionnaire. Then after, the questionnaire was given to the second reader to find out if it was well designed for the study.

\section{Statistical analyses}

We used SPSS 17.1 to enter the data into the database and performed analysis. We used the following five statistical methods to analyze the data:

\section{Descriptive statistics}

Descriptive statistics were used to compare PTSD symptoms severity before and after treatment. Percentages of participants in each category of severity intensity were calculated and compared before and after treatment to assess if there is any difference.

\section{Chi-square test}

Chi-square test was used to test the significance of differences between PTSD symptoms severity before and after treatment.

\section{Paired t-test}

Paired t-test was used to assess the efficacy of group therapy in reducing PTSD symptoms. Mean differences, standard deviations, standard error means, 95\% confidence intervals, t-test results, p-values helped to identify the differences between PTSD symptoms severity before and after treatment. To calculate t-test results the means and standard deviations of twenty symptoms of PTSD (According to DSM5) were compared in pairs before and after treatment. Pair1: represents $1^{\text {st }}$ symptom severity before and after treatment, Pair2: represents $2^{\text {nd }}$ symptom severity before and after treatment, Pair3: represents $3^{\text {rd }}$ symptom severity before and after treatment, Pair 4: represents $4^{\text {th }}$ symptom severity before and after treatment, Pair 5: represents $5^{\text {th }}$ symptom severity before and after treatment, Pair6: represents $6^{\text {th }}$ symptom severity before and after treatment, Pair7: represents $7^{\text {th }}$ symptom severity before and after treatment, Pair8: represents $8^{\text {th }}$ symptom severity before and after treatment, Pair 9: represents $9^{\text {th }}$ symptom severity before and after treatment, Pair 10: represents $10^{\text {th }}$ symptom severity before and after treatment, Pair 11: represents $11^{\text {st }}$ symptom severity before and after treatment, Pair12: represents $12^{\text {nd }}$ symptom severity before and after treatment, Pair13: 
represents $13^{\text {th }}$ symptom severity before and after treatment, Pair 14: represents $14^{\text {th }}$ symptom severity before and after treatment, Pair 15: represents $15^{\text {th }}$ symptom severity before and after treatment, Pair16: represents $16^{\text {th }}$ symptom severity before and after treatment, Pair17: represents $17^{\text {th }}$ symptom severity before and after treatment, Pair18: represents $18^{\text {th }}$ symptom severity before and after treatment, Pair19: represents $19^{\text {th }}$ symptom severity before and after treatment, and Pair 20: represents $20^{\text {th }}$ symptom severity before and after treatment (Table 5).

\section{Cohen's d test}

Cohen's d test was used to assess the significance of differences between symptoms severity before and after treatment by comparing the magnitude of effect sizes. The interpretation of these effect sizes refer to three categories based on benchmarks suggested by Cohen [10]. When $d=0.2$, it means that effect size is small, when $d=0.5$, it means that effect size is medium and when $d=0.8$, it means that effect size is large). Cohen's $d$ in between-subject designs can be readily interpreted as a percentage of the standard deviation, such that a Cohen's $d$ of 0.5 means the difference equals half a standard deviation.

\section{Fromula: Cohen's d (d) =Mean difference $(\mathrm{X}) /$ Standard deviation (SD)}

\section{Results}

\section{Social-demographic characteristics of participants}

The majority of participants were female, presenting $97.96 \%$ (96). Male presented only $2.04 \%$ (2) of all participants (Table 2). $13.27 \%$ (13) of all participants are single mothers, $14.29 \%$ (14) are legally married, $3.06 \%$ (3) are illegally married, $1.02 \%$ (1) of them are divorced, 5.1\% (5) are separated, $61.22 \%$ (60) are widows, $1.02 \%$ (1) is widower and $1.02 \%$ (1) is legally remarried (Table 3 ). $5.10 \%$ (5) of the participants are situated in the age group of $30-40$ years, $31.63 \%$ (31) are aged of $41-50$ years, $38.78 \%$ (38) of the participants were situated in the age group of $51-60$ years and $24.49 \%$ (24) of them were 61 year old and above (Table 3). 69.39\% (68) are crop farmers, $7.14 \%$ (7) of them are farmers, $1.02 \%$ (1) is student, $15.31 \%$ (15) do not have job, 5.10\% (5) are too old and cannot work, and $1.02 \%$ (1) is a self -worker and $1.02 \%$ (1) of them cooks in the restaurant (Table 3 ).

\section{Efficacy of group therapy in reducing PTSD symptoms and severity}

Descriptive statistics showed that the severity of PTSD symptoms was noticeably reduced after the treatment but chi-square results showed that the differences were statistically significant for only five (5) PTSD symptoms: (Marked physiological reactivity after exposure to trauma-related stimuli $\left[P=0.045, x^{2}=38.111\right]$; inability to recall key features of the traumatic event $\left[P<001, x^{2}=56.309\right]$; persistent negative trauma-related emotions $[P=0.013$, $\left.x^{2}=43.184\right]$; self-destructive or reckless behavior $\left[P=0.041, x^{2}=38.535\right]$; and hypervigilance $\left[P=0.020, x^{2}=41.596\right]$ (Table 4). Paired t-test and Cohen's d results showed significant differences between symptoms, before and after treatment; [Pair 1: $(t=15.054, P<0.001, d=1.52)$, Pair 2: $(t=14.003, P<0.001, d=1.41)$, Pair 3: $(t=15.599, P=0.000$, $d=1.58)$, Pair 4: $(t=13.444, P<0.001, d=1.33)$, Pair 5: $(t=10.330, P<0.001, d=1.04)$, Pair 6: $(t=8.883, P<0.001$, $d=0.90)$, Pair 7: $(t=8.265, P<0.001, d=0.84)$, Pair 8: $(t=2.785, P=0.006, d=0.28)$, Pair 9: $(t=19.613, P<0.001$, $d=1.98)$, Pair 10: (t=10.543, $P<0.001, d=1.07)$, Pair 11: $(t=4.933, P<0.001, P=0.001, d=1.51)$, Pair 12: $(t=14.902$, 
$P<0.001, d=1.51)$, Pair 13: $(t=14.074, P<0.001, d=1.42)$, Pair 14: $(t=12.471, P<0.001, d=1.27)$, Pair 15: $(t=12.282$, $P<0.001, d=1.25)$, Pair 16: $(t=12.935, P<0.001, d=1.31)$, Pair 17: $(t=11.860, P<0.001, d=1.20)$, Pair 18: ( $t=12.228$, $P<0.001, d=1.23)$, Pair 19: ( $t=13.051, P<0.001, d=1.32)$, Pair 20: $(t=11.694, P<0.001, d=1.18)]$ with $\mathrm{p}$-values less than $0.001(P<0.001)$ in all 20 pairs representing 20 PTSD symptoms (Table 5).

\section{Discussion}

To the best of our knowledge, only a few studies examined the mental health status of the Rwandan population in the aftermath of the Genocide, however, all findings showed that the percentages of those who suffer from mental health disorders, mainly depression and PTSD are very high[11][12][13]. As a result of the inhumane atrocity in which the genocide was committed, genocide survivors still require special quality care services notably appropriate health care services [14]. The main objective of this study was to analyze the efficacy of psychosocial group therapies created by AVEGA Agahozo in reducing PTSD symptoms among Genocide Survivors. According to the results found after performing analysis, demographic statistics indicated that women were $97.96 \%$ (96) of all participants and men presented only $2.04 \%$ (2) (Table 2). In terms of demographic variables, female gender is a commonly reported risk factor in the development of symptoms of depression and PTSD [15][16][17]. Previous findings consistently concluded that women are very prone to suffer from PTSD than men [18][19][20]. This difference in prevalence is also explained by how men were mostly targeted by perpetrators and were killed in Genocide than women. In 2004, Amnesty International showed that the widows were 10 times more than widowers, about 50,000 widows of the genocide [21]. A study conducted 25 years after the Genocide also found a very high prevalence rate of post-traumatic stress disorder among survivor mothers [9]. AVEGA Agahozo also mainly focuses on helping widows than widowers. 94.9\% (93) of all participants are 41 year and above (Table 2). That means that they were around 16 year old during the Genocide. Previous studies found that genocide survivors who were between the ages of 11 and 20 during the genocide are at the highest risk for PTSD [22]. All participants witnessed different traumatizing events that they went through during 1994 Genocide perpetrated against Tutsi and most of them experienced more than one traumatic event. Descriptive statistics showed that the severity of PTSD symptoms was dramatically reduced after treatment. However, these severity differences were only statistically significant for 5 PTSD symptoms: (Marked physiological reactivity after exposure to trauma-related stimuli; inability to recall key features of the traumatic event; persistent negative trauma-related emotions; self-destructive or reckless behavior and hypervigilance (Table 5). Paired t-test and Cohen's d results showed significant differences between symptoms severity before and after treatment with $\mathrm{p}$-values less than $0.001(P<0.001)$ in all 20 pairs representing 20 PTSD symptoms (Table 5). According to the results mentioned above, the present study concluded that the group therapy is effective to reduce the severity and symptoms of PTSD among Genocide survivors. These group therapies helped the genocide survivors to relieve the PTSD symptoms and regain hopes for a bright future. These results support the previous studies that stated that trauma centered group therapy effectively heals PTSD among a large number of combat veterans and non-military trauma victims of cruel violence and other disasters (like earthquake and hurricane) [23]. Based on the existing research, group treatment for PTSD appears to be an effective approach, although meta-analytic findings suggest that it is not as effective as individual therapy [24], thus further research should compare the effectiveness of group treatment and individual treatment. Most genocide survivors who suffer from PTSD do not go to the hospital to seek health care services and mental health disorder is one of the risks that might develop the complications of other diseases that can permanently harm the lives of genocide survivors. Prior study findings revealed that post-traumatic stress disorder, major 
depression disorder, and traumatic brain injuries can have long-lasting, and surging consequences such as substance abuse, suicide attempts, unhealthy behaviors, physical health problems, mortality, diminished productivity, and unemployment [25]. Children of trauma victims suffering from PTSD symptoms are also more likely to develop PTSD [26]. Some research findings consistently found that PTSD may persist longer after a traumatic event happened [2][3][4][5][6]. Post-traumatic stress disorder is still a substantial public health concern in Rwanda, and enabling people to have access to quality care for those who need it should be a national priority [22]. Thus, despite the great work made by the government of Rwanda to actively support reconciliation and reduce trauma, the magnitude of trauma among the Rwandan population remains essential over a decade after the Genocide [27]. Based on the findings of this study, we strongly recommend the use of group therapy for helping genocide survivors to recover from PTSD and improving their mental health and quality of life.

\section{Limitations}

There were some limitations while conducting this study. Firstly, the study did not assess the effect of group therapy longevity in healing PTSD symptoms. Secondly, the study did not assess how the intensity of traumatic events was associated with PTSD severity. Thirdly, the study used a small sample size due to the absence of many group therapies meeting inclusion criteria. Fourthly, the study did not analyze the effect of gender in recovering from PTSD because the sample was not proportionally distributed by gender.

\section{Strengths}

The interviews with participants were conducted by qualified psychologists and Diagnostic and Statistical Manual of Mental Disorders was used to diagnose the symptoms of PTSD among genocide survivors. This increased the accuracy and quality of data that were included in the analysis.

\section{Conclusion}

Psychosocial group therapies created by AVEGA Agahozo are effective in reducing PTSD symptoms and severity among genocide survivors.

\section{Abbreviations}

PTSD (Post-traumatic stress disorder)

DSM-5 (Diagnostic and Statistical Manual of Mental Disorders, fifth edition) AVEGA Agahozo (Association des veuves du Genocide, Agahozo)

\section{Declarations}

\section{Ethics approval and consent to participate}

This study has been approved by the research committee of Ningxia Medical University and AVEGA Agahozo after rigidly reviewed the design and intervention plan and evaluated the potential risks and possible harm to people involved in the research. All methods were performed in accordance with the relevant guidelines, regulations and principles of conducting research involving human subjects. All participants were allowed to 
withdraw from the study whenever they felt like they wanted to end the interview. Participation in this study was voluntary. All participants received informed consent before they participated in the study and the participation was approved by signing the consent form. All information was confidential and no names were mentioned in this study.

\section{Consent for publication}

Non-applicable

\section{Availability of data and materials}

The data analyzed and included in this study are accessible from the corresponding author after presenting a reasonable demand.

\section{Competing interests}

All authors declare no conflict of Interest

\section{Funding}

This study was partially supported by Ningxia Medical University. The funders did not participate in the conduct of the study, data collection, data entry, data analysis, preparedness of the manuscript and submission.

\section{Authors' contributions}

SIMBI checked the accuracy and quality of data, entered data in the database, performed the statistical analysis and drafted the manuscript. Seven psychologists (Names mentioned in the acknowledgement) collected the data (conducted the interviews), and all authors designed the study and revised the manuscript before submission.

\section{Acknowledgements}

The authors thank all genocide survivors who agreed to be interviewed; the psychologists that interviewed the participants (Ignace Rukundo, Ildephonse Ntezimana, Devotha Uzayisenga, Yvette Mukeshimana, Julienne Mukabahizi, Léandre Dufatanye, and Charité Ntwali) and AVEGA Agahozo for its support and technical assistance for the entire research work. Special gratitude also goes to the Finance department of Ningxia Medical University for supporting this study. We also thank Tujiza Uwituze for perusing this paper and her critical comments which were incorporated into the present version

\section{Authors' information}

1: Ph.D. candidate in the Department of Epidemiology and Health Statistics, School of Public Health and Management, Ningxia Medical University, 1160 Shengli Street, Yinchuan, Ningxia Hui Autonomous Region, China

1: Professor in the Department of Epidemiology and Health Statistics, School of Public Health and Management, Ningxia Medical University, 1160 Shengli Street, Yinchuan, Ningxia Hui Autonomous Region, China 
2: Professor in the Department of Epidemiology and Health Statistics, School of Public Health and Management, Ningxia Medical University, 1160 Shengli Street, Yinchuan, Ningxia Hui Autonomous Region, China

\section{References}

1. Hales R and Zatzick D 1997 What is PTSD? Am. J. Psychiatry 154 143-5

2. Kessler, R. C., Sonnega, A., Bromet, E., Hughes, M., Nelson, C. B., \& Breslau N (1999). 1999 Epidemiological risk factors for trauma and PTSD. In R. Yehuda (Ed.), Risk factors for posttraumatic stress disorder Arlington, VA, US Am. Psychiatr. Assoc. Abstr. 23-59

3. Rothbaum B O, Foa E B, Riggs D S, Murdock T and Walsh W 1992 A prospective examination of posttraumatic stress disorder in rape victims J. Trauma. Stress 5 455-75

4. Bramsen I and Ploeg H M 2007 Fifty years later: the long-term psychological adjustment of ageing World War II survivors Acta Psychiatr. Scand. 100 350-8

5. Yehuda R, Schmeidler J, Wainberg M, Binder-Brynes K and Duvdevani T 1998 Vulnerability to Posttraumatic Stress Disorder in Adult Offspring of Holocaust Survivors Am. J. Psychiatry 155 1163-71

6. Mollica R, Cardozo B L, Osofsky H, Raphael B, Ager A and Salama P 2004 Mental health in complex emergencies Lancet 364 2058-67

7. Heide Rieder;Thomas Elbert 2013 Rwanda - lasting imprints of Genocide: trauma, mental health and psychosocial conditions in survivors, former prisoners and their children. Confl. Health 76

8. Ministry of Health 2013 National Mental Health Policy in Rwanda

9. Mutuyimana C, Sezibera V, Nsabimana E, Mugabo L, Cassady C, Musanabaganwa C and Kayiteshonga $Y$ 2019 PTSD prevalence among resident mothers and their offspring in Rwanda 25 years after the 1994 genocide against the Tutsi BMC Psychol. 784

10. Cohen J 1977 The Concepts of Power Analysis Statistical Power Analysis for the Behavioral Sciences (Elsevier) pp 1-17

11. Bolton P, Neugebauer R and Ndogoni L 2002 PREVALENCE OF DEPRESSION IN RURAL RWANDA BASED ON SYMPTOM AND FUNCTIONAL CRITERIA J. Nerv. Ment. Dis. $190631-7$

12. Dyregrov A, Gupta L, Gjestad R and Mukanoheli E 2000 Trauma exposure and psychological reactions to genocide among Rwandan children J. Trauma. Stress 13 3-21

13. Schaal S and Elbert T 2006 Ten years after the genocide: Trauma confrontation and posttraumatic stress in Rwandan adolescents J. Trauma. Stress 19 95-105

14. Nzeyimana D, Nzayirambaho M and Ntakirutimana J 2014 "The Behaviour of the low income genocide survivors in case of illnesses: "Case of Kaduha, Cyanika and Mushubi Sectors of Nyamagabe District». Rwanda Med. J. 71 5-13

15. Brewin C R, Andrews B and Valentine J D 2000 Meta-analysis of risk factors for posttraumatic stress disorder in trauma-exposed adults. J. Consult. Clin. Psychol. 68 748-66

16. DiGrande L, Perrin M A, Thorpe L E, Thalji L, Murphy J, Wu D, Farfel M and Brackbill R M 2008 Posttraumatic stress symptoms, PTSD, and risk factors among lower Manhattan residents 2-3 years after the September 11, 2001 terrorist attacks J. Trauma. Stress 21 264-73 
17. Thapa S B and Hauff E 2005 Psychological distress among displaced persons during an armed conflict in Nepal Soc. Psychiatry Psychiatr. Epidemiol. 40 672-9

18. Breslau N, Kessler R C, Chilcoat H D, Schultz L R, Davis G C and Andreski P 1998 Trauma and Posttraumatic Stress Disorder in the Community Arch. Gen. Psychiatry 55626

19. Davidson J R T, Hughes D, Blazer D G and George L K 1991 Post-traumatic stress disorder in the community: an epidemiological study Psychol. Med. 21 713-21

20. Helzer J E, Robins L N and McEvoy L 1987 Post-Traumatic Stress Disorder in the General Population N. Engl. J. Med. 317 1630-4

21. Amnesty International 2004 Annual report

22. Munyandamutsa N, Mahoro Nkubamugisha P, Gex-Fabry M and Eytan A 2012 Mental and physical health in Rwanda 14 years after the genocide Soc. Psychiatry Psychiatr. Epidemiol. 47 1753-61

23. Rozynko V and Dondershine HE 1991 Trauma focus group therapy for Vietnam veterans with PTSD. Psychother. Theory, Res. Pract. Train. 28 157-61

24. Sloan D M, Feinstein B A, Gallagher M W, Beck J G and Keane T M 2013 Efficacy of group treatment for posttraumatic stress disorder symptoms: A meta-analysis. Psychol. Trauma Theory, Res. Pract. Policy 5 $176-83$

25. Lavelle E 2010 Recovery from Disability: Manual of Psychiatric Rehabilitation. Prof. RP Liberman American Psychiatric Publishing, Inc.; 1 edition. June 30, 2008. ISBN: 9781585622054 Ir. J. Psychol. Med. 27 53-53

26. Breslau N 1991 Traumatic Events and Posttraumatic Stress Disorder in an Urban Population of Young Adults Arch. Gen. Psychiatry 48216

27. Moore J 2009 Rwanda's genocide-15 years later (globalpost online)

\section{Tables}

Table 1: DSM-5: Criteria for PTSD 
1. The person was exposed to: death, threatened death, actual or threatened serious injury, or actual or threatened sexual violence

2. Intrusion symptoms (1/5 symptoms needed)

1. Recurrent, involuntary and intrusive recollections (children may express this symptom in repetitive play)

2. Traumatic nightmares (children may have disturbing dreams without content related to trauma)

3. Dissociative reactions (e.g. flashbacks) which may occur on a continuum from brief episodes to complete loss of consciousness (children may re-enact the event in play)

4. Intense or prolonged distress after exposure to traumatic reminders

5. Marked physiological reactivity after exposure to trauma-related stimuli

3. Persistent avoidance of stimuli associated with the trauma Persistent effortful avoidance of distressing trauma-related stimuli after the event (1/2 symptoms needed):

6. Trauma-related thoughts or feelings

7. Trauma-related external reminders (e.g. people, places, conversations, activities, objects or situations)

4. Negative alterations in cognitions and mood that began or worsened after the traumatic event (2/7 symptoms needed)

8. Inability to recall key features of the traumatic event (usually dissociative amnesia; not due to head injury, alcohol or drugs) (C3 in DSM-IV)

9. Persistent (\& often distorted) negative beliefs and expectations about oneself or the world (e.g. "I am bad," "the world is completely dangerous")(C7 in DSM-IV)

10. Persistent distorted blame of self or others for causing the traumatic event or for resulting consequences (new)

11. Persistent negative trauma-related emotions (e.g. fear, horror, anger, guilt, or shame) (new)

12. Markedly diminished interest in (pre-traumatic) significant activities (C4 in DSM-IV)

13. Feeling alienated from others (e.g. detachment or estrangement) (C5 in DSM-IV)

14. Constricted affect: persistent inability to experience positive emotions (C6 in DSM-IV)

5. Alterations in arousal and reactivity that are associated with the traumatic event $\mathrm{E}$. Trauma-related alterations in arousal and reactivity that began or worsened after the traumatic event (2/6 symptoms needed)

15. Irritable or aggressive behavior (revised D2 in DSM-IV)

16. Self-destructive or reckless behavior (new)

17. Hypervigilance (D4 in DSM-IV)

18. Exaggerated startle response (D5 in DSM-IV)

19. Problems in concentration (D3 in DSM-IV)

20. Sleep disturbance (D1 in DSM-IV)

a. Persistence of symptoms (in Criteria B, C, D and E) for more than one month

b. Significant symptom-related distress or functional impairment

c. Not due to medication, substance or illness

Table 2: Demographic characteristics of participants and selection 


\begin{tabular}{lllllll}
\hline & Male & \multicolumn{3}{l}{ Female } & \multicolumn{2}{l}{ Total } \\
\hline & Frequency & $\%$ & Frequency & $\%$ & Frequency & $\%$ \\
\hline $30-40$ & 0 & 0.00 & 5 & 5.10 & 5 & 5.10 \\
\hline $41-50$ & 0 & 0.00 & 31 & 31.63 & 31 & 31.63 \\
\hline $51-60$ & 0 & 0.00 & 38 & 38.78 & 38 & 38.78 \\
\hline 61 and above & 2 & 2.04 & 22 & 22.45 & 24 & 24.49 \\
\hline Total & 2 & 2.04 & 96 & 97.96 & 98 & 98.00 \\
\hline
\end{tabular}

Marital status of the participants

\begin{tabular}{llllllll} 
& Male & & Female & \multicolumn{3}{l}{ Total } \\
& Frequency & $\%$ & Frequency & $\%$ & Frequency & $\%$ \\
\hline Single mother & 0 & 0.00 & 13 & 13.27 & 13 & 13.27 \\
\hline Legally married & 1 & 1.02 & 13 & 13.27 & 14 & 14.29 \\
\hline Illegally married & 0 & 0.00 & 3 & 3.06 & 3 & 3.06 \\
\hline Divorced & 0 & 0.00 & 1 & 1.02 & 1 & 1.02 \\
\hline Separated & 0 & 0.00 & 5 & 5.10 & 5 & 5.10 \\
\hline Widow & 0 & 0.00 & 60 & 61.22 & 60 & 61.22 \\
\hline Widower & 1 & 1.02 & 0 & 0.00 & 1 & 1.02 \\
\hline Legally remarried & 0 & 0.00 & 1 & 1.02 & 1 & 1.02 \\
\hline Total & 2 & 2.04 & 96 & 97.96 & 98 & 98.00
\end{tabular}

\section{The profession of participants}

\begin{tabular}{lllllll} 
& Male & \multicolumn{3}{l}{ Male } & \multicolumn{3}{l}{ Total } \\
& Frequency & $\%$ & Frequency & $\%$ & Frequency & $\%$ \\
\hline Crop farmer & 2 & 2.04 & 66 & 67.35 & 68 & 69.39 \\
\hline Farmer & 0 & 0.00 & 7 & 7.14 & 7 & 7.14 \\
\hline Student & 0 & 0.00 & 1 & 1.02 & 1 & 1.02 \\
\hline I don't have a job & 0 & 0.00 & 15 & 15.31 & 15 & 15.31 \\
\hline Very old and cannot work & 0 & 0.00 & 5 & 5.10 & 5 & 5.10 \\
\hline Self-worker & 0 & 0.00 & 1 & 1.02 & 1 & 1.02 \\
\hline Cook in the restaurant & 0 & 0.00 & 1 & 1.02 & 1 & 1.02 \\
\hline Total & 2 & 2.04 & 96 & 97.96 & 98 & 98.00
\end{tabular}


Table 3: Subjects sampling procedures

\begin{tabular}{|c|c|c|c|}
\hline $\begin{array}{l}\text { Group } \\
\text { therapy }\end{array}$ & District & Sector & Cell \\
\hline
\end{tabular}

\begin{tabular}{lllllll}
\hline 1 & Gakenke & Rushashi & Kageyo & Nganze & 14 & 10 \\
\hline 2 & Rulindo & Kinzuzi & Mucembezo & Gatarage & 14 & 10 \\
\hline 3 & Musanze & Muhoza & Kigombe & Ndurume & 9 & 9 \\
\hline 4 & Gisagara & Kibirizi & Kibirizi & Torero & 18 & 10 \\
\hline 5 & Huye & Ngoma & Matyazo & Rusisiro & 9 & 9 \\
\hline 6 & Kayonza & Mukarange & Bwiza & Abisungane & 12 & 10 \\
\hline 7 & Bugesera & Nyamata & Nyamata & Nyamata1 & 15 & 10 \\
\hline 9 & Ngoma & Remera & Bugesera & Agatare & 12 & 10 \\
\hline 10 & Ngororero & Nyange & Gaseke & Ngobagobo & 15 & 10 \\
\hline Total & Nyamasheke & Kagano & Ninzi & Gikuyu & 16 & 10 \\
\hline
\end{tabular}

The above table shows the age, gender, marital status and occupation of participants along with participants' selection

Table 4: The efficacy of Group therapy in reducing PTSD symptoms and severity among Genocide survivors 


$\begin{array}{llll}\text { treatment } \quad \text { Pre- Post-treatment } & \begin{array}{l}\text { Chi- } \\ \text { square }\end{array} & \begin{array}{l}\text { P- } \\ \text { value/2- } \\ \text { sided }\end{array}\end{array}$

- 1. Recurrent, involuntary and intrusive recollections

\begin{tabular}{lllllll}
$\begin{array}{l}\text { PTSD Symptom } \\
\text { severity }\end{array}$ & Frequency & Percentage & Frequency & Percentage & \\
\hline Not at all & 1 & 1.0 & 24 & 24.5 & & \\
\hline Very slightly & 3 & 3.1 & 32 & 32.7 & & \\
\hline Slightly & 7 & 7.1 & 17 & 17.3 & & \\
\hline Moderately & 11 & 11.2 & 10 & 10.2 & 30.523 & 0.205 \\
\hline Quite a bit & 15 & 15.3 & 3 & 3.1 & & \\
\hline Extremely & 61 & 62.2 & 12 & 12.2 & & \\
\hline Total & 98 & 98.0 & 98 & 98.0 & &
\end{tabular}

\section{- 2. Traumatic nightmares}

\begin{tabular}{lllllll} 
Not at all & 4 & 4.1 & 24 & 24.5 & \\
Very slightly & 2 & 2.0 & 30 & 30.6 & & \\
\hline Slightly & 2 & 2.0 & 23 & 23.5 & & \\
\hline Moderately & 12 & 12.2 & 6 & 6.1 & 20.370 & 0.727 \\
\hline Quite a bit & 16 & 16.3 & 7 & 7.1 & & \\
\hline Extremely & 62 & 63.3 & 8 & 8.2 & \\
\hline Total & 98 & 98.0 & 98 & 98.0 & & \\
\hline
\end{tabular}

\section{Dissociative reactions}

\begin{tabular}{lllllll} 
Not at all & 1 & 1.0 & 21 & 21.4 & \\
Very slightly & 1 & 1.0 & 29 & 29.6 & & \\
\hline Slightly & 4 & 4.1 & 24 & 24.5 & & \\
\hline Moderately & 11 & 11.2 & 8 & 8.2 & 18.083 & 0.839 \\
\hline Quite a bit & 23 & 23.5 & 7 & 7.1 & & \\
\hline Extremely & 58 & 59.2 & 9 & 9.2 & \\
\hline Total & 98 & 98.0 & 98 & 98.0 & & \\
\hline
\end{tabular}

1. Intense or prolonged distress after exposure to traumatic reminders

$\begin{array}{lllll}\text { Not at all } & 2 & 2.0 & 23 & 23.5\end{array}$




\begin{tabular}{lllllll}
\hline Very slightly & 2 & 2.0 & 27 & 27.6 & & \\
\hline Slightly & 7 & 7.1 & 15 & 15.3 & & \\
\hline Moderately & 7 & 7.1 & 14 & 14.3 & 18.988 & 0.798 \\
\hline Quite a bit & 20 & 20.4 & 10 & 10.2 & & \\
\hline Extremely & 60 & 61.2 & 9 & 9.2 & & \\
\hline Total & 98 & 98.0 & 98 & 98.0 & &
\end{tabular}

1. Marked physiological reactivity after exposure to trauma-related stimuli

\begin{tabular}{lllllll} 
Not at all & 9 & 9.2 & 42 & 42.9 & \\
Very slightly & 6 & 6.1 & 26 & 26.5 & & \\
\hline Slightly & 11 & 11.2 & 14 & 14.3 & & \\
\hline Moderately & 16 & 16.3 & 5 & 5.1 & 38.111 & 0.045 \\
\hline Quite a bit & 14 & 14.3 & 4 & 4.1 & & \\
\hline Extremely & 42 & 42.9 & 7 & 7.1 & \\
\hline Total & 98 & 98.0 & 98 & 98.0 &
\end{tabular}

- 6. Trauma-related thoughts or feelings

\begin{tabular}{lllllll}
\hline Not at all & 13 & 13.3 & 39 & 39.8 & \\
\hline Very slightly & 3 & 3.1 & 21 & 21.4 & & \\
\hline Slightly & 7 & 7.1 & 13 & 13.3 & & \\
\hline Moderately & 11 & 11.2 & 7 & 7.1 & 37.017 & 0.058 \\
\hline Quite a bit & 20 & 20.4 & 3 & 3.1 & & \\
\hline Extremely & 44 & 44.9 & 15 & 15.3 & \\
\hline Total & 98 & 98.0 & 98 & 98.0 &
\end{tabular}

1. Trauma-related external reminders (e.g. people, places, conversations, activities, objects or situations

\begin{tabular}{lllllll} 
Not at all & 18 & 18.4 & 48 & 49.0 & & \\
\hline Very slightly & 5 & 5.1 & 15 & 15.3 & & \\
\hline Slightly & 6 & 6.1 & 12 & 12.2 & & \\
\hline Moderately & 5 & 5.1 & 7 & 7.1 & 36.563 & 0.063 \\
\hline Quite a bit & 19 & 19.4 & 2 & 2.0 & & \\
\hline Extremely & 45 & 45.9 & 14 & 14.3 & \\
\hline Total & 98 & 98.0 & 98 & 98.0 & & \\
& & Page 16/22 & & &
\end{tabular}


- 8. Inability to recall key features of the traumatic event (usually dissociative amnesia; not due to head injury, alcohol or drugs)

\begin{tabular}{lllllll} 
Not at all & 62 & 63.3 & 68 & 69.4 & & \\
\hline Very slightly & 4 & 4.1 & 10 & 10.2 & & \\
\hline Slightly & 9 & 9.2 & 8 & 8.2 & & \\
\hline Moderately & 3 & 3.1 & 4 & 4.1 & 56.309 & 0.000 \\
\hline Quite a bit & 8 & 8.2 & 4 & 4.1 & & \\
\hline Extremely & 12 & 12.2 & 4 & 4.1 & \\
\hline Total & 98 & 98.0 & 98 & 98.0 & &
\end{tabular}

- 9. Persistent (\& often distorted) negative beliefs and expectations about oneself or the world

\begin{tabular}{lllllll} 
Not at all & 4 & 4.1 & 74 & 75.5 & & \\
Very slightly & 3 & 3.1 & 13 & 13.3 & & \\
\hline Slightly & 9 & 9.2 & 2 & 2.0 & & \\
\hline Moderately & 6 & 6.1 & 1 & 1.0 & 15.193 & 0.937 \\
\hline Quite a bit & 20 & 20.4 & 5 & 5.1 & & \\
Extremely & 56 & 57.1 & 3 & 3.1 & & \\
\hline Total & 98 & 98.0 & 98 & 98.0 & &
\end{tabular}

- 10. Persistent distorted blame of self or others for causing the traumatic event or for resulting consequences

\begin{tabular}{lllllll} 
Not at all & 14 & 14.3 & 44 & 44.9 & & \\
\hline Very slightly & 2 & 2.0 & 20 & 20.4 & & \\
\hline Slightly & 10 & 10.2 & 10 & 10.2 & & \\
\hline Moderately & 13 & 13.3 & 12 & 12.2 & 27.503 & 0.331 \\
\hline Quite a bit & 22 & 22.4 & 4 & 4.1 & & \\
\hline Extremely & 37 & 37.8 & 8 & 8.2 & \\
\hline Total & 98 & 98.0 & 98 & 98.0 & & \\
\hline
\end{tabular}

- 11. Persistent negative trauma-related emotions (e.g. fear, horror, anger, guilt, or shame)

\begin{tabular}{lllll} 
Not at all & 9 & 9.2 & 42 & 42.9 \\
Very slightly & 1 & 1.0 & 25 & 25.5 \\
\hline Slightly & 5 & 5.1 & 15 & 15.3
\end{tabular}




\begin{tabular}{lllllll} 
Moderately & 5 & 5.1 & 3 & 3.1 & 43.184 & 0.013 \\
\hline Quite a bit & 15 & 15.3 & 8 & 8.2 & & \\
\hline Extremely & 63 & 64.3 & 5 & 5.1 & & \\
\hline Total & 98 & 98.0 & 98 & 98.0 &
\end{tabular}

- 12. Markedly diminished interest in (pre-traumatic) significant activities

\begin{tabular}{lllllll} 
Not at all & 13 & 13.3 & 72 & 73.5 & \\
\hline Very slightly & 4 & 4.1 & 15 & 15.3 & & \\
\hline Slightly & 8 & 8.2 & 3 & 3.1 & & \\
\hline Moderately & 9 & 9.2 & 2 & 2.0 & 25.423 & 0.439 \\
\hline Quite a bit & 16 & 16.3 & 4 & 4.1 & & \\
\hline Extremely & 48 & 49.0 & 2 & 2.0 & \\
\hline Total & 98 & 98.0 & 98 & 98.0 & &
\end{tabular}

- 13. Feeling alienated from others (e.g. detachment or estrangement)

\begin{tabular}{lllllll} 
Not at all & 9 & 9.2 & 60 & 61.2 & \\
Very slightly & 4 & 4.1 & 16 & 16.3 & & \\
Slightly & 4 & 4.1 & 7 & 7.1 & & \\
\hline Moderately & 5 & 5.1 & 5 & 5.1 & 21.263 & 0.678 \\
\hline Quite a bit & 21 & 21.4 & 8 & 8.2 & & \\
Extremely & 55 & 56.1 & 2 & 2.0 & \\
\hline Total & 98 & 98.0 & 98 & 98.0 & & \\
\hline
\end{tabular}

- 14. Constricted affect: persistent inability to experience positive emotions

\begin{tabular}{lllllll} 
Not at all & 6 & 6.1 & 42 & 42.9 & & \\
\hline Very slightly & 3 & 3.1 & 21 & 21.4 & & \\
\hline Slightly & 7 & 7.1 & 16 & 16.3 & & \\
\hline Moderately & 11 & 11.2 & 6 & 6.1 & 30.819 & 0.195 \\
\hline Quite a bit & 12 & 12.2 & 8 & 8.2 & & \\
\hline Extremely & 59 & 60.2 & 5 & 5.1 & \\
\hline Total & 98 & 98.0 & 98 & 98.0 & & \\
\hline
\end{tabular}

- 15. Irritable or aggressive behavior 


\begin{tabular}{lllllll} 
Not at all & 16 & 16.3 & 75 & 76.5 & \\
\hline Very slightly & 8 & 8.2 & 8 & 8.2 & & \\
\hline Slightly & 11 & 11.2 & 4 & 4.1 & & \\
\hline Moderately & 16 & 16.3 & 6 & 6.1 & 28.518 & 0.285 \\
\hline Quite a bit & 15 & 15.3 & 3 & 3.1 & & \\
\hline Extremely & 32 & 32.7 & 2 & 2.0 & \\
\hline Total & 98 & 98.0 & 98 & 98.0 & & \\
\hline
\end{tabular}

- 16. Self-destructive or reckless behavior

\begin{tabular}{lllllll} 
Not at all & 13 & 13.3 & 75 & 76.5 & & \\
\hline Very slightly & 6 & 6.1 & 12 & 12.2 & & \\
\hline Slightly & 5 & 5.1 & 3 & 3.1 & & \\
\hline Moderately & 18 & 18.4 & 3 & 3.1 & 0.041 \\
\hline Quite a bit & 16 & 16.3 & 1 & 1.0 & & \\
\hline Extremely & 40 & 40.8 & 4 & 4.1 & \\
\hline Total & 98 & 98.0 & 98 & 98.0 & &
\end{tabular}

\section{- 17. Hypervigilance}

\begin{tabular}{lllllll} 
Not at all & 9 & 9.2 & 35 & 35.7 & \\
Very slightly & 3 & 3.1 & 30 & 30.6 & & \\
\hline Slightly & 10 & 10.2 & 17 & 17.3 & 41.596 & 0.020 \\
\hline Moderately & 6 & 6.1 & 3 & 3.1 & & \\
\hline Quite a bit & 25 & 25.5 & 4 & 4.1 & \\
\hline Extremely & 45 & 45.9 & 9 & 9.2 & \\
\hline Total & 98 & 98.0 & 98 & 98.0 & \\
\hline
\end{tabular}

- 18. Exaggerated startle response

\begin{tabular}{|c|c|c|c|c|c|c|}
\hline Not at all & 7 & 7.1 & 37 & 37.8 & & \\
\hline Very slightly & 7 & 7.1 & 23 & 23.5 & & \\
\hline Slightly & 4 & 4.1 & 16 & 16.3 & & \\
\hline Moderately & 6 & 6.1 & 6 & 6.1 & 23.987 & 0.520 \\
\hline Quite a bit & 19 & 19.4 & 6 & 6.1 & & \\
\hline Extremely & 55 & 56.1 & 10 & 10.2 & & \\
\hline
\end{tabular}


98.0

- 19. Problems in concentration

\begin{tabular}{lllllll} 
Not at all & 7 & 7.1 & 55 & 56.1 & \\
\hline Very slightly & 4 & 4.1 & 16 & 16.3 & & \\
\hline Slightly & 9 & 9.2 & 10 & 10.2 & & \\
\hline Moderately & 8 & 8.2 & 6 & 6.1 & 0.787 & 0.704 \\
\hline Quite a bit & 32 & 32.7 & 6 & 6.1 & & \\
\hline Extremely & 38 & 38.8 & 5 & 5.1 & \\
\hline Total & 98 & 98.0 & 98 & 98.0 & & \\
\hline
\end{tabular}

\section{- 20. Sleep disturbance}

\begin{tabular}{lllllll}
\hline Not at all & 8 & 8.2 & 40 & 40.8 & & \\
\hline Very slightly & 1 & 1.0 & 14 & 14.3 & & \\
\hline Slightly & 7 & 7.1 & 13 & 13.3 & 28.848 & 0.270 \\
\hline Moderately & 9 & 9.2 & 14 & 14.3 & & \\
\hline Quite a bit & 12 & 12.2 & 10 & 10.2 & \\
\hline Extremely & 61 & 62.2 & 7 & 7.1 & \\
\hline Total & 98 & 98.0 & 98 & 98.0 & \\
\hline
\end{tabular}

\section{Table 5: Paired t-test results for pre and post-treatment}




\begin{tabular}{|c|c|c|c|c|c|c|c|c|c|c|}
\hline \multirow{2}{*}{\multicolumn{2}{|c|}{$\begin{array}{l}\text { Pairs } \\
\text { Pre-treatment-Post- } \\
\text { treatment }\end{array}$}} & \multicolumn{5}{|c|}{ Paired Differences } & \multirow[t]{3}{*}{$t$} & \multirow[t]{3}{*}{ df } & \multirow{3}{*}{$\begin{array}{l}\mathrm{P} \text { - } \\
\text { value }\end{array}$} & \multirow{3}{*}{$\begin{array}{l}\text { Cohen's } \\
\text { d }\end{array}$} \\
\hline & & \multirow[t]{2}{*}{ Mean } & \multirow[t]{2}{*}{$\begin{array}{l}\text { Std. } \\
\text { Deviation }\end{array}$} & \multirow[t]{2}{*}{$\begin{array}{l}\text { Std. } \\
\text { Error } \\
\text { Mean }\end{array}$} & \multicolumn{2}{|c|}{$\begin{array}{l}95 \% \\
\text { Confidence } \\
\text { Interval }\end{array}$} & & & & \\
\hline & & & & & Lower & Upper & & & & \\
\hline $\begin{array}{l}\text { Pair } \\
1\end{array}$ & $\begin{array}{l}\text { Recurrent, } \\
\text { involuntary } \\
\text { and intrusive } \\
\text { recollections }\end{array}$ & 2.520 & 1.657 & . 167 & 2.188 & 2.853 & 15.054 & 97 & .000 & 1.52 \\
\hline $\begin{array}{l}\text { Pair } \\
2\end{array}$ & $\begin{array}{l}\text { Traumatic } \\
\text { nightmares }\end{array}$ & 2.592 & 1.832 & .185 & 2.224 & 2.959 & 14.003 & 97 & .000 & 1.41 \\
\hline $\begin{array}{l}\text { Pair } \\
3\end{array}$ & $\begin{array}{l}\text { Dissociative } \\
\text { reactions }\end{array}$ & 2.551 & 1.619 & .164 & 2.226 & 2.876 & 15.599 & 97 & .000 & 1.58 \\
\hline $\begin{array}{l}\text { Pair } \\
4\end{array}$ & $\begin{array}{l}\text { Intense or } \\
\text { prolonged } \\
\text { distress after } \\
\text { exposure to } \\
\text { traumatic } \\
\text { reminders }\end{array}$ & 2.378 & 1.791 & .181 & 2.019 & 2.737 & 13.144 & 97 & .000 & 1.33 \\
\hline $\begin{array}{l}\text { Pair } \\
5\end{array}$ & $\begin{array}{l}\text { Marked } \\
\text { physiological } \\
\text { reactivity after } \\
\text { exposure to } \\
\text { trauma-related } \\
\text { stimuli }\end{array}$ & 2.265 & 2.171 & .219 & 1.830 & 2.701 & 10.330 & 97 & .000 & 1.04 \\
\hline $\begin{array}{l}\text { Pair } \\
6\end{array}$ & $\begin{array}{l}\text { Trauma-related } \\
\text { thoughts or } \\
\text { feelings }\end{array}$ & 1.990 & 2.218 & .224 & 1.545 & 2.434 & 8.883 & 97 & .000 & 0.90 \\
\hline $\begin{array}{l}\text { Pair } \\
7\end{array}$ & $\begin{array}{l}\text { Trauma-related } \\
\text { external } \\
\text { reminders }\end{array}$ & 1.990 & 2.383 & 241 & 1.512 & 2.468 & 8.265 & 97 & .000 & 0.84 \\
\hline $\begin{array}{l}\text { Pair } \\
8\end{array}$ & $\begin{array}{l}\text { Inability to } \\
\text { recall key } \\
\text { features of the } \\
\text { traumatic } \\
\text { event }\end{array}$ & .500 & 1.778 & .180 & .144 & .856 & 2.785 & 97 & .006 & 0.28 \\
\hline $\begin{array}{l}\text { Pair } \\
9\end{array}$ & $\begin{array}{l}\text { Persistent (\& } \\
\text { often } \\
\text { distorted) } \\
\text { negative } \\
\text { beliefs and } \\
\text { expectations } \\
\text { about oneself } \\
\text { or the world }\end{array}$ & 3.510 & 1.772 & .179 & 3.155 & 3.865 & 19.613 & 97 & .000 & 1.98 \\
\hline $\begin{array}{l}\text { Pair } \\
10\end{array}$ & $\begin{array}{l}\text { Persistent } \\
\text { distorted } \\
\text { blame of self } \\
\text { or others for } \\
\text { causing the } \\
\text { traumatic } \\
\text { event or for }\end{array}$ & 2.061 & 1.947 & .197 & 1.671 & 2.452 & 10.481 & 97 & .000 & 1.06 \\
\hline
\end{tabular}


resulting

consequences

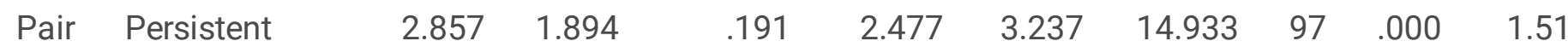

11 negative

trauma-related

emotions

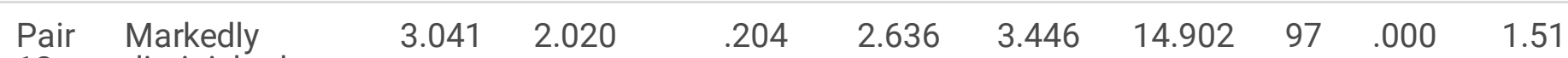

12 diminished

interest in (pre-

traumatic)

significant

activities

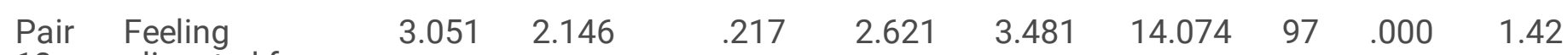

13 alienated from

others

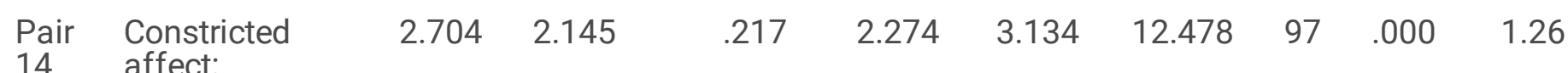

persistent

inability to

experience

positive

emotions

Pair Irritable or

15 aggressive

$2.469 \quad 2.006$

$.203 \quad 2.067$

2.872

12.185

$97 \quad 000 \quad 1.23$

behavior

$\begin{array}{llllllllll}\text { Pair Self- } & 2.888 & 2.210 & .223 & 2.445 & 3.331 & 12.935 & 97 & .000 & 1.31\end{array}$

16 destructive or

reckless

behavior

$\begin{array}{lllllllllll}\begin{array}{l}\text { Pair } \\ 17\end{array} & \text { Hypervigilance } & 2.367 & 1.976 & .200 & 1.971 & 2.764 & 11.860 & 97 & .000 & 1.20\end{array}$

\begin{tabular}{lllllllllll}
$\begin{array}{l}\text { Pair } \\
18\end{array}$ & $\begin{array}{l}\text { Exaggerated } \\
\text { startle } \\
\text { response }\end{array}$ & 2.418 & 1.958 & .198 & 2.026 & 2.811 & 12.228 & 97 & .000 & 1.23 \\
$\begin{array}{l}\text { Pair } \\
19\end{array}$ & $\begin{array}{l}\text { Problems in } \\
\text { concentration }\end{array}$ & 2.663 & 2.020 & .204 & 2.258 & 3.068 & 13.051 & 97 & .000 & 1.32 \\
$\begin{array}{l}\text { Pair } \\
20\end{array}$ & $\begin{array}{l}\text { Sleep } \\
\text { disturbance }\end{array}$ & 2.429 & 2.056 & .208 & 2.016 & 2.841 & 11.694 & 97 & .000 & 1.18 \\
\hline
\end{tabular}

Table 5 shows mean, standard deviation, standard error mean, 95\% confidence interval, t-test results, degree of freedom, p-values and Cohen'd effect sizes. 